\title{
Transthoracic Needle Biopsy
}

National Cancer Institute

\section{Source}

National Cancer Institute. Transthoracic Needle Biopsy. NCI Thesaurus. Code $C 113773$.

A diagnostic procedure in which a needle is inserted in the thoracic cavity to detect lesions of the pleura, lung parenchyma, or mediastinum. 